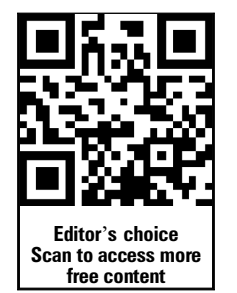

- Additional material is published online only. To view please visit the journal online (http://dx.doi.org/10.1136/jech2013-203624)

${ }^{1}$ Epidemiological Centre on Medical Causes of Death (CépiDc), National Institute of Health and Medical Research (INSERM), Le Kremlin-Bicêtre, France

${ }^{2}$ Assistance PubliqueHôpitaux de Paris (APHP) Paris, France

\section{Correspondence to} Dr Grégoire Rey, CépiDcInserm, Hôpital Bicêtre, 80, rue du Général Leclerc, Secteur marron-Bâtiment La ForcePorte 58, Le Kremlin-Bicêtre 94270, Cedex, France: gregoire.rey@inserm.fr

Received 8 November 2013 Revised 26 March 2014 Accepted 30 May 2014 Published Online First 18 June 2014

\section{SLinked}

- http://dx.doi.org/10.1136/ jech-2014-204487

\section{CrossMark}

To cite: Laanani $M$, Ghosn W, Jougla E, et al. J Epidemiol Community Health 2015:69:103-109.

\title{
Impact of unemployment variations on suicide mortality in Western European countries (2000-2010)
}

\author{
Moussa Laanani, ${ }^{1,2}$ Walid Ghosn, ${ }^{1}$ Eric Jougla, ${ }^{1}$ Grégoire Rey ${ }^{1}$
}

\section{ABSTRACT}

Background A scientific debate is currently taking place on whether the 2008 economic crisis caused an increase in suicide rates. Our main objective was to assess the impact of unemployment rate on suicide rate in Western European countries between 2000 and 2010. We then tried to estimate the excess number of suicides attributable to the increase of unemployment during the 2008-2010 economic crisis.

Methods The yearly suicide rates were modelled using a quasi-Poisson model, controlling for sex, age, country and a linear time trend. For each country, the unemployment-suicide association was assessed, and the excess number of suicides attributable to the increase of unemployment was estimated. Sensitivity analyses were performed, notably in order to evaluate whether the unemployment-suicide association found was biased by a confounding context effect ('crisis effect').

Results A significant $0.3 \%$ overall increase in suicide rate for a $10 \%$ increase in unemployment rate $(95 \% \mathrm{Cl}$ $0.1 \%$ to $0.5 \%$ ) was highlighted. This association was significant in three countries: $0.7 \%(95 \% \mathrm{Cl} 0.0 \%$ to $1.4 \%)$ in the Netherlands, $1.0 \%(95 \% \mathrm{Cl} 0.2 \%$ to $1.8 \%)$ in the $\mathrm{UK}$ and $1.9 \%(95 \% \mathrm{Cl} 0.8 \%$ to $2.9 \%)$ in France, with a significant excess number of suicides attributable to unemployment variations between 2008 and 2010 (respectively 57, 456 and 564). The association was modified inconsistently when adding a 'crisis effect' into the model.

Conclusions Unemployment and suicide rates are globally statistically associated in the investigated countries. However, this association is weak, and its amplitude and sensitivity to the 'crisis effect' vary across countries. This inconsistency provides arguments against its causal interpretation.

\section{INTRODUCTION}

Since Durkheim's classic sociological study on suicide at the end of the nineteenth century, ${ }^{1}$ increases in suicides during economic downturns are repeatedly observed. However, it remains important to clearly define the actual origin of this increase in order to target it with effective public health policies. In 2008, Western European countries had entered in a period of economic crisis, characterised by a slowdown in economic activity with sharp rises in unemployment rates. A debate is currently taking place about its public health consequences, particularly on an increase of deaths by suicide due to economic downturns. This debate is fuelled by media headlines on a rise in suicides linked to unemployment or fear of job loss (with, for instance, in France, the succession of suicides at the national telecom company). ${ }^{2}$ The scientific discussion is focused on whether the economic crisis has caused the observed increase in suicides. ${ }^{3-9}$

Becoming unemployed is a stressful event, introducing some loss of social roles, and can trigger a feeling of entrapment leading a person to suicide. ${ }^{10}$ The individual unemployment-suicide association is already well documented. ${ }^{10-12}$ Unemployment was thus the feature used by most of the studies assessing the impact of the 2008 economic crisis on suicide. $^{3} 681314$ However, these studies have an ecological design: they assess associations between unemployment and suicide rates with aggregated data instead of individual data. Two components of the ecological association are generally distinguished: the individual effect (or 'composition effect'), defined as the impact of becoming unemployed on suicidal behaviour on individuals, and the contextual effect, defined as the social phenomena (job insecurity among employed population, family and friends of unemployed persons) induced by unemployment variations on suicide mortality of the whole population. These two components cannot be distinguished by ecological studies, but they should be both considered in interpreting the results. Caution must be taken with the risk of ecological fallacy: ecological association must not be interpreted only as individual associations. Hence, the overall consequence of unemployment on suicide rates can be explained at the ecological level as a combination of the individual effect (more unemployed people die by suicide) and of the contextual effect on the labour market. Unemployment increase develops tension and anxiety on the labour market, notably by the fear of job loss among employed people. ${ }^{15} 16$ These feelings of job insecurity could foster an increase in suicide rates, as suicide mortality increases among employed people when unemployment rates increase in the population. ${ }^{17} 18$

This unemployment-suicide ecological association could be biased by the confounding effects of concomitant features of the economic crisis (hereinafter gathered in the term 'crisis effect'). The economic crisis could impact on suicide mortality by unemployment increase, but also by the effect of other features, whose list is difficult to draw up. The impact of fear of job loss is already known, ${ }^{15} 16$ but we can also hypothesise an impact of governmental or private firm policy shifts, or an impact of the way the media handle the consequences of the economic crisis. As an impact of the reporting of suicides in the media has been 
described as an imitation, or social contagion process, ${ }^{19-22}$ we can hypothesise that the media could sustain a climate of socioeconomic decline and insecurity, responsible for hopelessness among the population. The impact of unemployment is highly correlated with the impact of the other features of the economic crisis (or 'crisis effect'), making them difficult to study independently.

The ecological impact of the 2008 economic crisis on suicide rates has been studied in different countries. ${ }^{3}$ 6-9 142324 Mixed results were obtained because of the use of different methodologies and also because the studies took into account either the effect of unemployment or the 'crisis effect'. Despite this inconsistency, and the blurred definition of the assessed exposition (unemployment or crisis), a causal association between the 2008 economic crisis and the increase in suicides was suggested. ${ }^{3} 59$ One of these studies assessed the 'crisis effect' on suicide mortality in 54 countries all over the world ${ }^{9}$ and found an association between the magnitude (in percentage points) of rises in unemployment and increases in men suicide mortality. The investigators deduced a dose-response effect, consistent with the hypothesis of a causal role of the 2008 economic crisis on rises in suicide mortality.

A recent study found that expenses on labour market policies could mitigate the public health consequences of economic crises, including the increase in suicides. ${ }^{25}$ Then, we expect the association to be heterogeneous between countries. Specifically, as France has one of the highest employment protection indexes according to the OECD ${ }^{26}$ the impact of unemployment variations on suicide rate in this country should be low. France also appears with one of the highest suicide rates among Western European countries, ${ }^{27}$ suggesting that France deserves a focus on the issue of the unemployment-suicide association.

This study aimed to assess the ecological effect of unemployment rate on suicide rate in Western European countries between 2000 and 2010. Sensitivity analyses were undertaken to assess the robustness of the model regarding different hypotheses, notably regarding a possible confounding 'crisis effect'. The analysis provided an estimation of the excess number of suicides attributable to the increase of unemployment in each country during the 2008-2010 economic crisis.

\section{METHODS}

Data

Suicide numbers (ICD-10 codes X60-X84) ${ }^{28}$ were collected for Western European countries from Eurostat database by sex, 5 -year age group (from 15-19 years to 85 years and over), country and year of death for the period 2000-2010. ${ }^{29}$ Corresponding population counts and unemployment rates were also obtained from Eurostat. The analysis was focused on the Western European countries (ie, the 15 member states of the European Union in 1995). Among them were excluded, in order to keep sufficient statistical power, those where the number of suicides was lower than 1000 per year (Denmark, Greece, Ireland, Luxembourg and Portugal) and those with missing data for suicide (Belgium and Italy). Finally, the countries included in the analyses were Austria, Finland, France, Germany, the Netherlands, Spain, Sweden and the UK.

More refined French data, regarding the region of residence and the quarter of death, were available from the Epidemiological Centre on Medical Causes of Death $\left(\right.$ CépiDc-INSERM) ${ }^{30}$ and were used for further analyses. Corresponding yearly population counts and quarterly regional unemployment rates were obtained from the National Institute of Statistics and Economic Studies (INSEE). ${ }^{31}$

\section{Statistical analyses}

The yearly suicide rates in European countries were modelled using a quasi-Poisson model, handling overdispersion. An interaction term was introduced between sex, age and country in order to account for the heterogeneous distribution of suicide rates according to age and sex across countries. ${ }^{32}$ A linear time trend $\mathrm{t}(\mathrm{y})$ was inserted in order to consider the underlying suicide mortality trend. This trend was interacted with country, age and sex in order to take into account its statistical heterogeneity. The relative variation of unemployment rate compared with that of 2000 was used to assess the unemployment-suicide association. The choice of relative unemployment instead of absolute unemployment was motivated by the model deviance that was slightly lower for relative unemployment. The relative risks obtained concern a $10 \%$ increase in unemployment rate. Relative unemployment was interacted with the country in order to obtain national relative risks. The following model was finally retained:

(E1):

$$
\begin{aligned}
\log \left(\lambda_{s, a, c, y}\right)= & \log \left(\operatorname{pop}_{s, a, c, y}\right)+\alpha_{s, a, c}+\left(\beta_{1, c}+\beta_{2, a}+\beta_{3, s}\right) \times t(y) \\
& +\gamma_{c} \times \text { UnemployVar }_{y}
\end{aligned}
$$

where $\lambda$ refers to the expected value of the number of suicides for a sex (s), an age (a), a country (c) and a year (y), and pop the corresponding population count; $t(y)$ is the linear time trend, and UnemployVar the 10\% variation of unemployment rate; $\alpha, \beta$ and $\gamma$ are the coefficients to be estimated by the model. National relative risks of suicide for a $10 \%$ variation of unemployment rate are obtained with the exponential of $\gamma$.

The equations of the sensitivity analyses are presented in the online supplementary resource: E2 and E3 are analyses held on the same European data than the main model (E1); F1, F2 and F3 are analyses held on French refined data.

In E2, a dummy variable (Crisis), taking the value 0 for 2000-2007 and 1 for 2008-2010, was introduced by country to estimate the 'crisis effect' on suicide rates and to assess whether the association between suicide mortality and unemployment obtained with the previous model was confounded by a 'crisis effect'. In E3, the time trend terms were suppressed to evaluate the sensitivity of our model to the hypothesis of the existence of an independent linear time trend in suicide mortality, allowing to assess whether unemployment variations could explain all temporal variations in suicide mortality.

$\mathrm{F} 1$, on regional and yearly data, assessed whether the results observed with E1 could be modified by using a geographical smaller-scale analysis. F2, on regional and quarterly data, assessed the impact of taking into account a region-specific seasonality of suicide mortality. F3, on regional and quarterly data, assessed a 3, 6 and 12-month lag effect of unemployment variations on suicide mortality.

The main model (E1) was used to estimate the excess number of suicides attributable to unemployment variations for the period 2008-2010. The baseline number of suicides was defined as the number of suicides predicted by the model for the period 2008-2010 if the unemployment rate was that of the last quarter of 2007. The expected number of suicides was defined as the number of suicides predicted by the model for the period 2008-2010, with the observed unemployment rate. The excess number of suicides attributable to unemployment variations during the 2008-2010 economic crisis was the difference between the expected number of suicides and the baseline 
number of suicides. CI of this estimation was calculated using the bootstrap method. ${ }^{33}$ The estimation of the excess number of suicides in France and its CI were controlled on French refined data by using the most complete model (F2).

Modelling was conducted in R (V2.15.2). ${ }^{34}$
RESULTS

In the eight countries included in the analyses, unemployment rate rose between 2008 and 2009 (figure 1). This increase was varying from 0.3 percentage point in Germany to 6.7 percentage points in Spain. In most of the countries, the
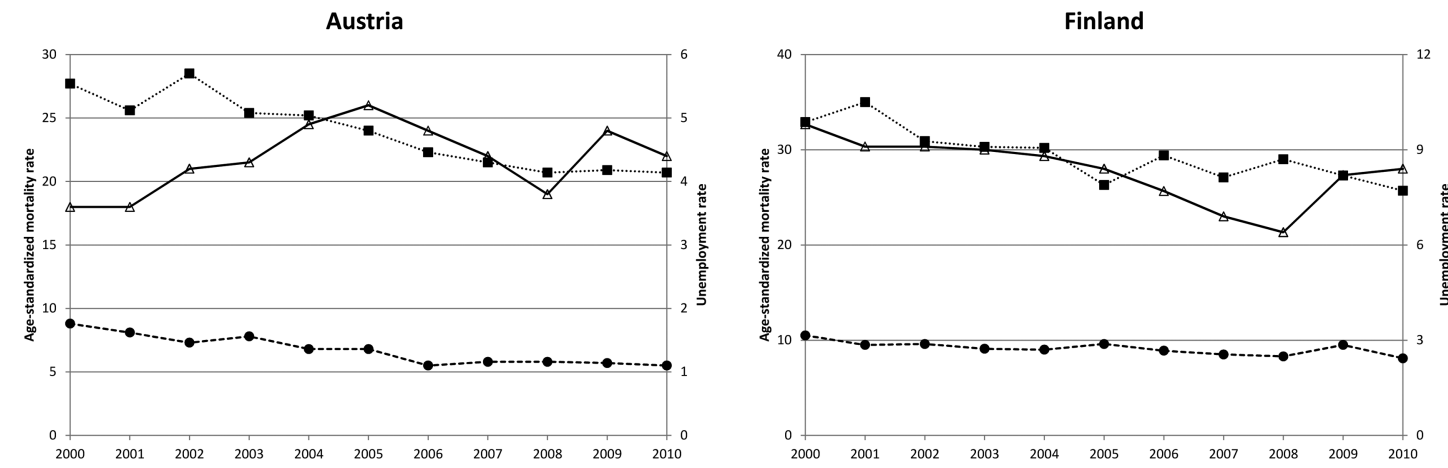

France
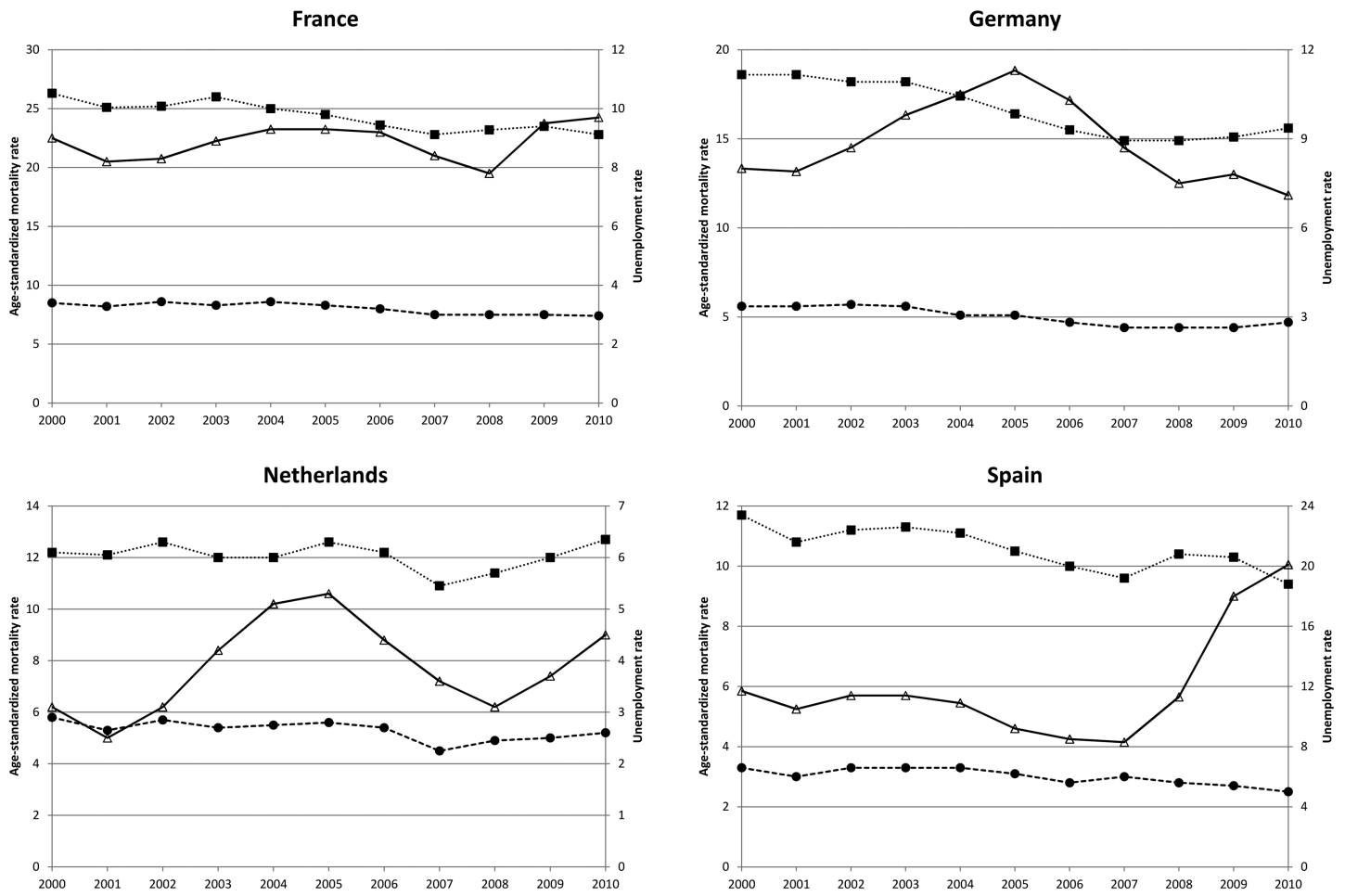

Sweden
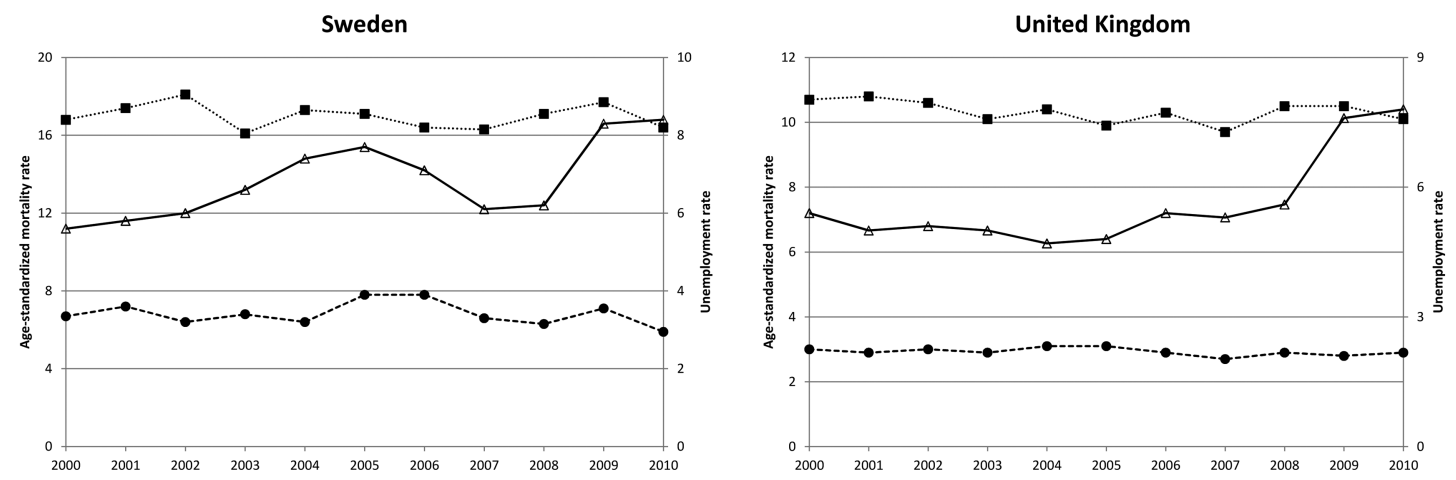

Figure 1 Age-standardised suicide rates (per 100000 inhabitants, reference population: IARC1976) for men and women, and corresponding unemployment rates (\%) for both sexes, by country, 2000-2010 (source: Eurostat). Filled squares: age-standardised mortality rate for suicide (men); filled rounds: age-standardised mortality rate for suicide (women); unfilled triangles: unemployment rate. Scales are not comparable across countries. 
age-standardised rate of suicides in men rose between 2008 and 2009, but it remained stable in the UK, and decreased slightly in Spain and more strongly in Finland. Women suicide rates remained nearly stable between 2008 and 2009, with a variation of suicide rate between -0.1 and +0.1 per 100000 inhabitants in all countries except Sweden $(+0.8)$ and Finland $(+1.2)$.

Overall, including the eight studied countries, the unemployment-suicide association observed with the main model was statistically significant, with a $0.3 \%$ increase in suicide rate for a $10 \%$ increase in unemployment rate $(95 \%$ CI $0.1 \%$ to $0.5 \%)$. Considering each country, the association was found significant in France, the UK and the Netherlands (table 1). The strongest central estimation of the association was observed in France, with a $1.9 \%$ increase in suicide rate for a $10 \%$ increase in unemployment rate (95\% CI $0.8 \%$ to $2.9 \%$ ).

The overall relative risk associated with unemployment was not modified when adding a 'crisis effect' into the model (model E2), even if this 'crisis effect' was statistically significant $(R R=1.033, p<0.001$, see table 2). Nevertheless, in some countries, this addition changed the results. In Germany, where no association was found with the first model, a significant association was highlighted with $\mathrm{E} 2(\mathrm{RR}=1.009, \mathrm{p}<0.01)$ with a significant 'crisis effect' $(R R=1.074, p<0.001)$. In the $U K$, the significant association found in E1 disappeared in E2, with a significant 'crisis effect' $(\mathrm{RR}=1.074, \mathrm{p}<0.01)$. When the temporal trend was suppressed (model E3), results were deeply changed from E1 for all countries, notably with a significant negative association between suicide and unemployment in Austria and Spain.

In France, results obtained from regional yearly data (F1) and from regional quarterly data (F2) were slightly changed from $\mathrm{E} 1: \quad \mathrm{RR}=1.015 \quad(\mathrm{p}<0.001)$ for $\mathrm{F} 1$ and $\mathrm{F} 2, \quad \mathrm{RR}=1.019$ $(p<0.001)$ for E1 (table 3). The association was reduced when considering an increasing lag time between employment rate and mortality by suicide (model F3).

Compared with what would be expected if unemployment rate stayed at the level of the last quarter of 2007, the excess number of suicides attributable to unemployment variations during the 2008-2010 economic crisis was significant in France, the UK and the Netherlands (respectively 564, 456 and 57 excess suicides, table 4). This estimation was conducted on French regional and quarterly data with the most complete model (F2) as a sensitivity analysis, and very similar results were obtained (584 excess suicides, 95\% CI 234 to 886, instead of $564,95 \%$ CI 277 to 845 with E1).

\section{DISCUSSION}

This study highlights that, in Western Europe, when unemployment rises, suicides rise globally for the investigated countries. However, the association observed with the main model (E1) is slight (a $0.3 \%$ increase in suicide rates for a $10 \%$ increase in unemployment rate) and varies according to the country (it was significant only in three countries: the Netherlands $(0.7 \%)$, the UK (1.0\%) and France (1.9\%)). This inconsistent association was already described in a previous study for the period 19731983. ${ }^{17}$ In Spain, no unemployment-suicide association was highlighted, whereas it has the strongest increase in unemployment of the eight countries, in line with a previous study. ${ }^{8}$ Furthermore, the unemployment-suicide relation found was very sensitive to two main hypotheses: a confounding context effect of the economic crisis (or 'crisis effect') and a linear time trend of suicide mortality. This sensitivity varied across countries.

The first hypothesis, tested with the model E2, was that the effect of unemployment on suicide could be explained by a 'crisis effect'. This 'crisis effect' could be the result of the social impact of political decisions such as budgetary cutbacks. Previous studies found that the way suicides are reported by the media is associated with suicide mortality. ${ }^{19-22}$ Then, the way the media report, and eventually over-report, the socioeconomic consequences of the crisis (lowered economic outlook, falling household power, etc.) could be another causal path of the 'crisis effect' on suicide. The consequences of adjusting on the 'crisis effect' were different across countries. In the UK, this adjustment made the observed unemployment-suicide association disappear, with a significant positive 'crisis effect', while it remained unchanged in France. This suggests that the unemployment-suicide association observed in E1 was differentially confounded by this 'crisis effect'. This could be explained, for example, by disparities in the reporting of the socioeconomic consequences of the crisis by the media. Distinguishing the actual origin of the increase in suicides during the economic crisis would help to implement efficient policies.

The second hypothesis was that unemployment could not explain all the variations of suicide mortality, but only its

Table 1 Relative risks of increase in suicide rates by country, for a 10\% increase in unemployment rate, during the period $2000-2010$

\begin{tabular}{|c|c|c|c|c|c|c|}
\hline \multirow{2}{*}{$\begin{array}{l}\text { Model } \\
\text { Country }\end{array}$} & \multicolumn{2}{|l|}{ E1 } & \multicolumn{2}{|c|}{ E2 (with 'crisis effect') } & \multicolumn{2}{|c|}{ E3 (without time trend) } \\
\hline & RR & $95 \% \mathrm{Cl}$ & RR & $95 \% \mathrm{Cl}$ & RR & $95 \% \mathrm{Cl}$ \\
\hline Austria & 1.003 & 0.989 to 1.017 & 1.012 & 0.994 to 1.031 & 0.964 & 0.948 to $0.980^{* * *}$ \\
\hline Finland & 0.996 & 0.965 to 1.027 & 0.987 & 0.957 to 1.019 & 1.054 & 1.026 to $1.083^{* * *}$ \\
\hline France & 1.019 & 1.008 to $1.029^{* * *}$ & 1.020 & 1.009 to $1.031^{* * *}$ & 0.995 & 0.982 to 1.007 \\
\hline Germany & 0.999 & 0.995 to 1.003 & 1.009 & 1.002 to $1.015^{* *}$ & 1.011 & 1.006 to $1.016^{* * *}$ \\
\hline Netherlands & 1.007 & 1.000 to $1.014^{*}$ & 1.013 & 1.005 to $1.021^{* *}$ & 1.003 & 0.995 to 1.012 \\
\hline Spain & 1.000 & 0.996 to 1.005 & 0.997 & 0.991 to 1.003 & 0.989 & 0.984 to $0.994^{* * *}$ \\
\hline Sweden & 1.009 & 0.993 to 1.026 & 1.009 & 0.993 to 1.026 & 1.003 & 0.989 to 1.018 \\
\hline UK & 1.010 & 1.002 to $1.018^{*}$ & 1.000 & 0.990 to 1.010 & 0.997 & 0.990 to 1.004 \\
\hline Overall & 1.003 & 1.001 to $1.005^{*}$ & 1.004 & 1.001 to $1.006^{* *}$ & 0.998 & 0.996 to 1.001 \\
\hline
\end{tabular}


variations after adjustment on its time trend. The comparison of the results of the models E3 and E1 shows that modelling is deeply sensitive to this time trend hypothesis. Adjusting on this trend is justified by the general reduction in overall mortality such as in suicide mortality observed from 2000 to $2010 .{ }^{29}$ It is also a way to adjust on potential effects of prevention campaigns and treatments on suicides and suicide attempts. ${ }^{35}$ A linear time trend is probably the safer choice compared with a nonlinear trend in this study as our study period is relatively short (11 years) and has few data points. However, such adjustment, while reasonable, is not based on specific mechanistic hypotheses. Further analyses should adjust models on actual factors of variation (eg, the implementation of public health policies) rather than on vaguely defined effects.

Using more refined data to perform the French estimations, taking into account the regional variability in reporting suicide $^{36}$ (F1) and suicide seasonality ${ }^{37}$ (F2), slightly weakened the associations. This result argues that the association is only slightly sensitive to the choice of the spatial scale. French refined data allowed also to assess whether there is a time-lag effect of unemployment on suicide (F3). Our results highlight an immediate effect of unemployment variations on suicides in French general population.

Although France has one of the highest OECD employment protection indexes among the analysed countries, ${ }^{26}$ it has the strongest central estimation of the unemployment-suicide association, with a $1.9 \%$ increase in suicide rate for a $10 \%$ increase in unemployment rate. This is an unexpected result on the basis of the conclusions of Stuckler and collaborators' study, ${ }^{25}$ which found that expenses on labour market policies could mitigate the increase in suicides during economic crises. Nonetheless, we regretted to have to exclude some countries hardly affected by the economic crisis (particularly, Greece, Ireland, Portugal and Italy). This choice allowed us to keep sufficient statistical power to highlight unbiased associations, but restrains the generalisability of our results to comparable countries.

Our study, based on aggregated data, cannot formally distinguish the contextual from the individual effect. It was not designed to assess whether unemployed people are more likely to die by suicide than employed people. This individual association was already demonstrated, ${ }^{11}$ but without concluding on an established causal link, regarding possible confounders including mental illness. ${ }^{11} 38$ This individual association may

Table 2 Relative risks of increase in suicide rates by country, during the economic crisis period 2008-2010, compared to the period 2000-2007, according to the model E2

\begin{tabular}{|c|c|c|}
\hline Country & RR & $95 \% \mathrm{Cl}$ \\
\hline Austria & 1.070 & 0.981 to 1.167 \\
\hline Finland & 1.077 & 0.998 to 1.163 \\
\hline France & 1.016 & 0.992 to 1.040 \\
\hline Germany & 1.074 & 1.036 to $1.115^{* * *}$ \\
\hline Netherlands & 1.107 & 1.027 to $1.193^{* *}$ \\
\hline Spain & 1.042 & 0.984 to 1.103 \\
\hline Sweden & 1.008 & 0.940 to 1.081 \\
\hline UK & 1.074 & 1.024 to $1.127^{* *}$ \\
\hline Overall & 1.033 & 1.019 to $1.047^{* * *}$ \\
\hline
\end{tabular}

Table 3 Relative risks of increase in suicide rates in France, for a $10 \%$ increase in unemployment rate, during the period 2000-2010: sensitivity analyses conducted on refined data

\begin{tabular}{lll}
\hline Model & RR & $95 \%$ Cl \\
\hline E1 (results for France) & 1.019 & 1.008 to $1.029^{* * *}$ \\
F1 (regional data) & 1.015 & 1.006 to $1.023^{* * *}$ \\
F2 (regional and quarterly data) & 1.015 & 1.007 to $1.023^{* * *}$ \\
F3 (3-month lag effect) & 1.011 & 1.004 to $1.019^{* *}$ \\
F3 (6-month lag effect) & 1.007 & 0.999 to 1.014 \\
F3 (12-month lag effect) & 0.997 & 0.990 to 1.003 \\
\hline${ }^{*} p<0.05$. & & \\
${ }^{* *} p<0.01$. & \\
${ }^{* * *}$ p $<0.001$. & \\
RR, relative risk. &
\end{tabular}

explain a part of the positive unemployment-suicide association found. This study, like most ecological studies of this kind, allowed to evaluate not only suicides of unemployed people but also by others around them and more generally suicides attributable to pressures on the labour market. ${ }^{15} \mathrm{~A}$ weakness of ecological studies is that they cannot conclude on a causal association. However, Bradford Hill's criteria ${ }^{39}$ can be applied to these studies to support cautious causal interpretation. An individual longitudinal study would be helpful to support our findings, but it requires a very large cohort to have enough statistical power as suicides remain relatively rare events.

Another limitation of our study is that differences exist between countries in suicide reporting. ${ }^{36}$ In France, for example, the underestimation of suicide number was estimated at $9.4 \%$ in $2006 .{ }^{40}$ However, on this 11 -year study period, the declaration bias is likely to remain reasonably stable within a country, ${ }^{5}{ }^{36}$ allowing us to evaluate suicide rate variations. Nevertheless, the estimations of excess numbers of suicides across countries strongly depend on the quality and comparability of suicide reporting: they have to be interpreted as the excess number of reported suicides. These unparalleled reporting rates led us to use a one-level model. Alternatively, a hierarchical model (with years nested within countries, and a country random effect) would search to explain these differences between countries. We preferred to only adjust our models on the country, eliminating the need of a country random effect.

Our results are not comparable with Chang and collaborators' study because, apart from the fact that their model was different from ours, they estimated the excess number of suicides attributable to the economic crisis ${ }^{9}$ while we estimated more specifically

Table 4 Excess number of suicides attributable to unemployment variations during the 2008-2010 economic crisis

\begin{tabular}{lcr}
\hline Country & Excess number of suicides & \multicolumn{1}{c}{$95 \% \mathrm{Cl}$} \\
\hline Austria & 9 & -36 to 52 \\
Finland & -21 & -147 to 104 \\
France & 564 & 277 to 845 \\
Germany & 23 & -77 to 113 \\
Netherlands & 57 & 9 to 104 \\
Spain & 28 & -240 to 274 \\
Sweden & 122 & -81 to 296 \\
UK & 456 & 126 to 763 \\
\hline
\end{tabular}


the excess number of suicides attributable to unemployment rate variations during the crisis. Our estimation concludes to 564 excess suicides between 2008 and 2010 in France, 456 in the UK and 57 in the Netherlands. These are not small numbers and, considering the unreported suicides (of which rates strongly vary across countries), suicide attempts and suicidal ideations, these figures should be considered as the tip of the iceberg of the consequences of the 2008 economic crisis on suicidal behaviour.

Is unemployment increase causal in the rise of suicide rates? Some authors argued that this causal link was already established and that now is the time to think about how to mitigate this public heath effect of the financial crisis. ${ }^{5}$ Nonetheless, our results tend to temper these interpretations. Although our study highlights a significant unemployment-suicide association, the latter is actually rather weak (in France, where the central estimation of the association is the strongest, there is a $1.9 \%$ increase in suicide rate for a $10 \%$ increase in unemployment rate). Moreover, the results of this study are strongly sensitive to the hypothesis of a linear trend in suicide mortality, as shown by the results of the model E3. The unemployment-suicide associations found across countries are inconsistently confounded by a 'crisis effect'. This single ecological study cannot bring a causal conclusion. However, the inconsistent association it highlighted does not come in favour of its causal interpretation. Identifying the actual origins of suicide increase during the financial crisis appears essential in order to implement efficient public health policies.

\section{What is already known on this subject}

- Increases in suicides during economic downturns are a recurrent observation since the end of the nineteenth century. Suicides have also increased during the 2008 economic crisis in most of countries.

- Economic crisis can impact on suicide mortality by many ways, notably by the increase of unemployment. However, the causal nature of the unemployment-suicide association remains discussed.

- Previous studies on the impact of the 2008 economic crisis on suicide mortality found inconsistent associations.

\section{What this study adds}

- The ecological unemployment-suicide association is inconsistently confounded across countries by the effect of concomitant features of the economic crisis.

- The unemployment-suicide association, currently discussed by scientists, should not be considered as causal, at least at the ecological level.

- Distinguishing the effect of unemployment from the effect of other concomitant features of the economic crisis is important, particularly in times of economic downturn, in order to implement efficient preventive policies, by targeting the actual origin of the increase in suicide mortality.

Acknowledgements We are very grateful to Gérard Pavillon and Alexandre Blake for their skilful assistance in the preparation of the English version of this manuscript.
Contributors ML contributed to the analysis and interpretation of data and drafted the manuscript. WG contributed to the statistical design of the study. EJ contributed to the interpretation of data and revised the manuscript. GR designed and supervised the study.

Funding This research was supported by the French National Institute of Health and Medical Research.

Competing interests None.

Provenance and peer review Not commissioned; externally peer reviewed.

\section{REFERENCES}

1 Durkheim É. [Suicide, a study in sociology]. Paris: Presses universitaires de France, 1897.

2 Chrisafis A. Wave of staff suicides at France Telecom. The Guardian [Internet]. 9 September 2009 [cited 2013 Apr 3]. http://www.guardian.co.uk/world/2009/sep/09/ france-telecom-staff-suicides-phone

3 Barr B, Taylor-Robinson D, Scott-Samuel A, et al. Suicides associated with the 2008-10 economic recession in England: time trend analysis. BMJ 2012:345: e5142.

4 Fountoulakis KN, Siamouli M, Grammatikopoulos IA, et al. Economic crisis-related increased suicidality in Greece and Italy: a premature overinterpretation. J Epidemiol Community Health 2013:67:379-80.

5 De Vogli R, Marmot M, Stuckler D. Strong evidence that the economic crisis caused a rise in suicides in Europe: the need for social protection. J Epidemiol Community Health 2013:67:298

6 Saurina C, Bragulat B, Saez $M$, et al. A conditional model for estimating the increase in suicides associated with the 2008-2010 economic recession in England. J Epidemiol Community Health 2013;67:779-87.

7 Lopez Bernal JA, Gasparrini A, Artundo CM, et al. The effect of the late 2000s financial crisis on suicides in Spain: an interrupted time-series analysis. Eur J Public Health 2013;23:732-6.

8 Ayuso-Mateos JL, Barros PP, Gusmão R. Financial crisis, austerity, and health in Europe. Lancet 2013;382:391-2.

9 Chang S-S, Stuckler D, Yip P, et al. Impact of 2008 global economic crisis on suicide: time trend study in 54 countries. BMJ 2013;347:f5239.

10 Hawton K, van Heeringen K. The international handbook of suicide and attempted suicide. Chichester: John Wiley \& Sons, Ltd, 2000.

11 Blakely TA, Collings SCD, Atkinson J. Unemployment and suicide. Evidence for a causal association? J Epidemiol Community Health 2003;57:594-600.

12 Cohidon C, Santin G, Geoffroy-Perez B, et al. [Suicide and occupation in France]. Rev Epidemiol Sante Publique 2010;58:139-50.

13 Stuckler D, Basu S, Suhrcke M, et al. Effects of the 2008 recession on health: a first look at European data. Lancet 2011:378:124-5.

14 Reeves $A$, Stuckler D, McKee $M$, et al. Increase in state suicide rates in the USA during economic recession. Lancet 2012;380:1813-14.

15 Reichert A, Tauchmann H. The causal impact of fear of unemployment on psychological health. Essen: Rheinisch-Westfälisches Institut für Wirtschaftsforschung, 2011

16 Milner A, Kavanagh A, Krnjacki L, et al. Area-level unemployment and perceived job insecurity: evidence from a longitudinal survey conducted in the Australian working-age population. Ann Occup Hyg 2014;58:171-81.

17 Crombie IK. Can changes in the unemployment rates explain the recent changes in suicide rates in developed countries? Int J Epidemiol 1990;19:412-16.

18 Yip PSF, Caine ED. Employment status and suicide: the complex relationships between changing unemployment rates and death rates. J Epidemiol Community Health 2011:65:733-6.

19 Chen Y-Y, Yip PSF, Lee C, et al. Economic fluctuations and suicide: a comparison of Taiwan and Hong Kong. Soc Sci Med 2010;71:2083-90.

20 Chen $Y-Y$, Liao S-F, Teng P-R, et al. The impact of media reporting of the suicide of a singer on suicide rates in Taiwan. Soc Psychiatry Psychiatr Epidemiol 2012;47:215-21.

21 Niederkrotenthaler T, Voracek M, Herberth A, et al. Role of media reports in completed and prevented suicide: Werther v. Papageno effects. Br J Psychiatry 2010;197:234-43.

22 Gould MS. Suicide and the media. Ann N Y Acad Sci 2001;932:200-21; discussion 221-224.

23 Fountoulakis KN, Savopoulos C, Siamouli M, et al. Trends in suicidality amid the economic crisis in Greece. Eur Arch Psychiatry Clin Neurosci 2013;263:441-4.

24 De Vogli R, Marmot M, Stuckler D. Excess suicides and attempted suicides in Italy attributable to the great recession. J Epidemiol Community Health 2013;67:378-9.

25 Stuckler D, Basu S, Suhrcke M, et al. The public health effect of economic crises and alternative policy responses in Europe: an empirical analysis. Lancet 2009:374:315-23.

26 OECD Indicators of Employment Protection [Internet]. OECD. [cited 2013 Aug 5]. http://www.oecd.org/employment/emp/oecdindicatorsofemploymentprotection.htm 
27 Death due to suicide, by sex: Standardised death rate by 100000 inhabitants [Internet]. Eurostat. [cited 2013 Aug 5]. http://epp.eurostat.ec.europa.eu/tgm/table. do?tab=table\&plugin $=1$ \&language $=$ en\&pcode $=t$ ps 00122

28 International Statistical Classification of Diseases and Related Health Problems, Tenth Revision. WHO, 2008.

29 Official European statistics [Internet]. Eurostat. [cited 2013 Aug 5]. http://epp. eurostat.ec.europa.eu/portal/page/portal/statistics/themes

30 French national cause of death register (Epidemiological Centre on Medical Causes of Death) [Internet]. CépiDc-INSERM. [cited 2013 Aug 5]. http://www.cepidc.inserm. fr/inserm/html/index2.htm

31 French National Institute of Statistics and Economic Studies [Internet]. INSEE. [cited 2013 Aug 5]. http://www.insee.fr/en/default.asp

32 Suicide rates by age groups and by gender [Internet]. WHO. [cited 2013 Aug 5]. http://www.who.int/mental_health/prevention/suicide/country_reports/en/index.html

33 Carpenter J, Bithell J. Bootstrap confidence intervals: when, which, what? A practical guide for medical statisticians. Stat Med 2000;19:1141-64.
34 R. Vienna, Austria: The R Foundation for Statistical Computing.

35 Gusmão R, Quintão S, McDaid D, et al. Antidepressant utilization and suicide in Europe: an ecological multi-national study. PLOS ONE 2013;8:e66455.

36 Jougla E, Rossolin F, Niyonsenga A, et al. Comparability and quality improvement of European causes of death statistics-final report. European Commision-DG Sanco Agreement, 2001.

37 Rocchi MBL, Sisti D, Cascio MT, et al. Seasonality and suicide in Italy: amplitude is positively related to suicide rates. J Affect Disord 2007;100:129-36.

38 Milner A, Page A, Lamontagne AD. Cause and effect in studies on unemployment, mental health and suicide: a meta-analytic and conceptual review. Psychol Med 2013. Epub ahead of print.

39 Bradford-Hill A. The environment and disease: association or causation? Proc $R$ Soc Med 1965;58:295-300

40 Aouba A, Péquignot F, Camelin L, et al. [Quality assessment and improvement in the knowledge of suicide mortality data, metropolitan France, 2006]. Bull Epidémiol Hebd 2011;47-48:497-500. 